\title{
Twin Data: The Lives That Drive the Findings/Twin Research Reviews: Twin Concordance for Kleine-Levin Syndrome; Twin Study of Political Discussion; Twin Relationship Quality and Urinary Cortisol Level; Twin Research Guide/In the News: Twins' Same Day Deliveries; Death of a Twin Holocaust Survivor; Identical Vindman Twins; Twin Festival in France; Tiniest Twins
}

\author{
Nancy L. Segal \\ Department of Psychology, California State University, Fullerton, CA, USA
}

\begin{abstract}
Twin data and the results generated by research are driven by the behavioral and physical attributes of twin participants. However, many investigators working with twin data have limited personal contact with actual twin-pairs. This situation may be limiting with respect to interpretation of results and formulation of new hypotheses. In an attempt to rectify this issue, key aspects of the interconnected lives of co-twins in three monozygotic male twin-pairs are presented. The section that follows includes a review of twin research on KleineLevin syndrome, political discussion, twin relationship quality and urinary cortisol level, and guidelines for determining sample sizes. The final part of this report presents twin-related news items relating to twins' same day deliveries, death of a twin Holocaust survivor, the Vindman twins, a twin festival in France and the tiniest twins on record.
\end{abstract}

\section{Twin Data: The Lives That Drive the Findings}

Twin data maintained by local, national and international registries have proliferated exponentially in recent years. This impressive progress in twin research had enabled numerous investigations across areas as diverse as cognition, personality, pregnancy, epigenetics and genomewide association, to name a few. The downside of this circumstance is that many investigators working with twin data have enjoyed little experience observing and thinking about the personal details of twins' lives, information that can significantly shape their interpretation of results and formulation of new hypotheses. Thus, the aim of this article is to present a close look at the lives of three monozygotic (MZ) twin-pairs that variously relate to the relationship they share and the relationship they lost.

The three twin-pairs I have selected are male, but that was not a conscious decision on my part. Instead, the pairs were chosen because they are, or promise to be, better known in the future, and because they have beautifully articulated key aspects of their twinship. The information I will present has been drawn solely from the twins' autobiographical accounts. Zygosity was established

Author for correspondence: Nancy L. Segal, Email: nsegal@fullerton.edu

Cite this article: Segal NL. (2020) Twin Data: The Lives That Drive the Findings/Twin Research Reviews: Twin Concordance for Kleine-Levin Syndrome; Twin Study of Political Discussion; Twin Relationship Quality and Urinary Cortisol Level; Twin Research Guide/ In the News: Twins' Same Day Deliveries; Death of a Twin Holocaust Survivor; Identical Vindman Twins; Twin Festival in France; Tiniest Twins. Twin Research and Human Genetics 23: 61-65, https://doi.org/10.1017/thg.2020.9 by their physical identity that caused many people, even those who knew them well or who did not know they had a twin, to confuse them from time to time. While DNA testing is the most accurate assessment of twin type, it is widely acknowledged that the question 'Are you as alike as two peas in a pod?' yields $98 \%$ accuracy of twin classification when compared with findings from five independent blood group systems (Cederlöf et al., 1961; also see Segal, 2017).

\section{The Twin Relationship: Marcus and Alex Lewis}

The compelling story of British twins Marcus and Alex Lewis was the focus of a 2019 documentary film, Tell Me Who I Am, directed by Ed Perkins. The film, based largely on a best-selling book with the same title, opened to critical acclaim; the book was co-written with author Joanna Hodges and published in 2013 (Lewis \& Lewis, 2013). I have both seen the film and read the book. I learned about the film from a friend - I am fortunate in that articles, clippings and other twin-related information are sent my way from many sources.

Marcus and Alex were born in 1964 to their mother Jill Dudley and her late husband, John Lewis. Lewis passed away when the twins were just three weeks old. The cause of his death was a car accident in which Alex was thrown from the car and sustained a fractured skull. Marcus was not in the car at the time, remaining in the maternity hospital due to an infection, but Alex was well enough to be brought home before him. The twins were raised by their mother's new husband, Jack Dudley, who they 
presumed to be their father. Dudley was initially warm and accepting of the young twins, but ultimately turned cold and abusive toward them. Both twins suffered from dyslexia, which interfered with their educational progress, a situation that Dudley made worse by his insulting comments. They feared him.

The twins' lives from childhood until they turned 18 years of age were both ordinary and extraordinary. To the outside world they were polite, obedient and the closest of brothers. They were always together as children, and nicknamed 'Ali'n'Marky' and 'MarcusandAli'. However, there were dark secrets - the twins lived in a shed that was separate from their large family home ('Duke's Cottage') and lacked heating and plumbing. More importantly, the twins were subjected to constant sexual abuse by their mother and her friends. They later discovered that their younger brother, but not their sister, suffered similarly.

A life-changing event happened to Alex when the twins were 18, causing a significant change in their close relationship. Alex had a serious motorcycle accident, fracturing his skull for a second time, an especially serious physical insult given the earlier injury. When he awakened in the hospital a week later the first person he noticed was Marcus, who had remained at his bedside for most of the time. Alex recognized his brother immediately, but his memory for all events that had happened to him and his family had been destroyed. Alex did not know his mother or anyone else and became completely dependent on Marcus to fill him in on his past and present. Marcus did so, but created a world that did not include the sexual abuse to which the brothers had been subjected. This decision was Marcus's way of not only protecting his twin, but of coping with his own trauma; he made the past go away. Marcus had never before concealed information from his brother, but he did so this time out of love and self-protection. Their bond was never broken; in fact, as adults they travelled together and collaborated on a number of different projects. However, over the years, Alex gradually learned that there were family secrets. In an emotional sequence at the end of the film Marcus finally shared his memories with his twin.

A vast accumulation of twin studies shows that the relationship between MZ twins is especially close, and closer than that of dizygotic (DZ) twins, on average (see Segal, 2017 and references therein). When twins complete questionnaires or engage in experimental tasks concerning their intrapair relations, the outcomes of such studies are driven by their understanding, intimacy and acceptance - qualities exemplified by Marcus and Alex.

\section{Self-Analysis of the Loss of a Twin: George and Frank Engel}

When I was in my first year of graduate school at the University of Chicago, a fellow student invited me to an event at the Chicago Psychoanalytic Institute. A professor of psychiatry at the University of Rochester School of Medicine, Dr George L. Engel, would be delivering the Helen Rose Lecture titled 'Mourning and Anniversary Reactions to the Death of a Twin'. My theoretical framework was behavioral-genetic, but psychoanalysts provide insightful biographical details in their case reports, so I was eager to attend. The presentation was riveting, and in those days of letter writing, I contacted Dr Engel to obtain a copy of his lecture that was eventually published (Engel, 1975). He complied, and in his letter he wrote, 'You know why it is meaningful for me to have responses'. The lecture and published article differ somewhat in some sections, but I cite information from the lecture only because hearing it in person effectively highlighted the significance of losing an MZ twin. I would eventually conduct a large-scale study of twin loss at the University of Minnesota and California State University, Fullerton (Segal, 2019a).

George and Frank Engel were born on December 10, 1913. They were known as 'the twins', never calling each other by name, but instead using the term 'Oth'. This label derived from 'other man', which they began using with reference to each other at the age of two years. Engel explained that the two words eventually coalesced into 'Othie' and then 'Oth'. They spent more time together than with anyone else, becoming a complementary unit. They communicated partly through private words, behavior that delayed their language development, which is not atypical for twins (see Segal, 2017). Their closeness increased their desire to become as alike as possible, which they also viewed as an advantage. However, there was rivalry between them growing up - what Engel calls 'calibrated aggression', in which they controlled their physical aggression toward one another. Both twins eventually became doctors, receiving their training at the same college, medical school and internship. At this point, they separated when George joined the Peter Brent Brigham Hospital in medicine and Frank became affiliated with Yale University in biochemistry. When Frank passed away, he was a Professor of Medicine at Duke University and George was a Professor of Medicine at the University of Rochester.

Frank passed away suddenly at the age of 49 years due to a myocardial infarction. It was this sudden event that led to George's self-analysis of content from dreams, coupled with attention to anniversary dates involving the death of his father and twin. For example, it turned out that he was also at risk for a heart condition and believed he would not survive beyond the age of 58, his father's age at death. Some of his dreams included confusion between himself and his twin. In reality, he was often confused for Frank, and at a lecture was even introduced as Frank. Such mistaken identity was a source of amusement when both twins were alive, but became a painful reminder following Frank's death. On one occasion, George was addressed as Frank by a stranger, yet he let the remark go uncorrected. He interpreted this as reinforcement for their fused identities.

George Engel's concluding remarks stress that the material in his article should be regarded as data. Here, data include the 'form and sequence of the presentation, the formulations, the omissions and elisions .... and even the motivation to write the paper in the first place'. He goes on to say, 'To the extent that the paper is wellreceived I have established the narcissistic gratification of the last twinship' (Engel, 1974, p. 28). Regardless of one's theoretical orientation, this article is well worth reading for the rich autobiographical account of an identical twinship. Here again, the twins' personal relationship would drive the data were they to have participated in a twin study.

\section{Individual Experience as Collective: Norris and (Alan) Ross McWhirter}

In 2014-2015, I was hired as a consultant for the Guinness Book of Records (GBR) to provide updated information regarding all aspects of twinning. This experience heightened my interest in MZ twins, Norris and Ross McWhirter, the founders of the GBR. The twins shared a fascination with 'records and superlatives' that they felt might not be widespread among others, but they were wrong. The first volume of their GBR series, a slim green-covered book of 200 pages, appeared on August 27, 1955 and grew enormously in popularity (McWhirter, 1976). 
The jacket cover notes that the GBR has outsold every other book except the Bible.

Ross: The Story of a Shared Life (McWhirter, 1976) is a booklength tribute to a twin brother who was shot in November 1975 by suspected Irish Republican Army (IRA) terrorists in retaliation for his launching of the Beat-the-Bombers campaign and related activities. Ross was a television broadcaster in addition to his role as a co-editor of the GBR. The book offers a comprehensive overview of the twins' childhood years in the London borough of Enfield, their education at the local kindergarten before attending the Chesterton boarding school, Oxford University and the Royal Navy. Their sports participation as athletes and reporters is covered, as is their joint company registered in March 1951, which they called a 'Press and Periodical Features Service'. Their mission was to provide facts and figures to newspapers, encyclopedias and other information sources - perhaps the forerunner of the GBR. Black and white photographs distributed throughout the book show that the twins maintained their identical physical appearance as they aged.

The intense close relationship between these twin brothers is skillfully expressed by Norris, the surviving twin. On hearing of his twin's sudden death he recalled, 'As I was being driven back through the roadblock in a policeman's sports car with my head under a blanket, I felt that I was about to be reborn - not as half a person but as a double person' (McWhirter, 1976, p. 5). He did not elaborate on that statement, but it suggests that it fell on him to carry on his brother's work. He did continue to edit the GBR and established the Ross McWhirter Foundation, whose mission was to combat tyranny (Barker, 2004).

McWhirter believed that nontwins, and even some twins, do not and cannot comprehend the intimacy that some identical twins enjoy. According to Norris, he and his twin brother shared every success, failure, aspiration, hope fulfilled, hope lost, tragedy, triumph and worry. Here is another example of how common goals and interests guide twins' responses to questions on twin loss surveys and other inventories. MZ twin survivors express slightly, but significantly, greater grief intensity than DZ twin survivors, mirroring the nature and quality of their social relations. I have, however, suspected that the twin group differences I reported are not larger because most twins are volunteers, so such studies would attract mostly MZ twins and the subset of DZ twins who are especially bereaved (Segal, 2019a). Data from more representative twin samples would offer a truer picture of responses to the loss of an identical or a fraternal twin.

\section{Twin Research Reviews}

\section{Twin Concordance for Kleine-Levin Syndrome}

In a previous issue of Twin Research and Human Genetics, I cited a study by Peraita-Adrados et al. (2012) as the only report of MZ twins concordant for Kleine-Levin syndrome (KLS); see Segal (2019b). I explained that KLS is a genetically based condition that includes recurrent hypersomnia (excessive sleeping that can last for days), in addition to other symptoms, such as (but not limited to) compulsive eating, confusion and impaired speech. In response to that paper, I received a note from Neal Farber, $\mathrm{PhD}$, former Co-President of the KLS Foundation and the father of two children who were affected with the condition for a period of 10 years. Farber has also tracked multiplex families with the disorder (Nguyen et al., 2016).

Farber noted that another case report of MZ twin concordance for KLS had been in 2012, by Japanese researchers (Ueno et al.,
2012). The twins in questions were 18 -year-old MZ male twins whose KLS onset was apparently triggered by infection from influenza. Their observations suggested that KLS may be linked to genetic and autoimmune factors, although the relationship between KLS and specific human leukocyte antigen (HLA) type is controversial.

\section{Twin Study of Political Discussion}

Genetic influences on political behavior have been of interest, focusing on measures such as political participation (Baker et al., 2006) and political attitudes (Hatemi \& Verhulst, 2015). However, relatively less attention has been directed toward genetic influences on political discussion. A paper reporting two twin studies of political discussion is now available (York, 2019). The first study included 167 twin-pairs (138 MZ, $29 \mathrm{DZ}$ ) from the Annual Twins Days Festival held in 2017 in Twinsburg, Ohio. The second study included 578 twin-pairs (347 MZ, $231 \mathrm{DZ)}$ ) identified from the Minnesota Twin Registry (Minnesota Twins Political Survey) in 2008 and 2009. A caveat is that festival twins were diagnosed as MZ or DZ based on simply asking each participant if they were part of an identical or fraternal pair. This type of self-assignment can be quite unreliable, and differs from the single question described in the first section of this article. However, twin festivals tend to attract MZ twins and the composition of the sample is largely MZ. An item regarding zygosity for the Minnesota twins was available from the registry, but the specific item was not indicated.

Items concerning frequency of political discussion, online political participation and response to expressed political conflict were variously completely by the twins. Both studies found that, on average, $40.63 \%$ of the variance in political discussion was explained by genetic factors. However, the proportion of genetic variance varied from $13 \%$ (discomfort during political talk) to $64 \%$ (frequency of political talk) for more specific measures. Future studies should include additional items pertaining to this interesting area and indicate the methods by which zygosity was determined.

\section{Twin Relationship Quality and Urinary Cortisol Level}

Genetic and environmental influences on physiological measures are important to examine. A recent study explored the relationship between co-twins as a moderator of genetic and environmental influences on urinary cortisol levels (Schwartz et al., 2019). Twin were identified from the Midlife in the United States (MIDUS), a longitudinal study with a nationally representative participant sample. The final sample, drawn from the Biomarker Study, included 298 twin individuals (156 MZ, 86 DZ same sex and 56 opposite sex). It was noted that zygosity was indeterminate for 14 individuals, and co-twins were not included in the project in the case of 80 individuals. Unfortunately, the methods by which zygosity was assessed were not provided.

Twins provided 12-hour urine samples and completed several key questions concerning their twin relationship. The main findings were that (1) MZ twins reported a higher composite score on the twin relationship questions than DZ twins; (2) genetic factors explained $42 \%$ of the variance, whereas nonshared environmental factors explained $58 \%$ of the variance; (3) co-twin contact and urinary cortisol levels were significantly correlated for MZ twins, but not for DZ twins or for the sample as a whole; and (4) genetic influence on urinary cortisol level was higher when twins shared a closer 
relationship. This last finding is consistent with the concept that greater genetic expression is expected when environments are less restrictive. Thus, a close twin relationship may afford freedom of action and expression to its members. Future studies of physiological and other measures may wish to consider this measure in their analyses.

\section{Twin Research Guide}

Australian researchers recently created a helpful guide for determining the number of twin-pairs necessary for conducting a classic MZ-DZ twin comparison (Dite et al., 2019). Tables display the desired sample sizes by trait and by different MZ and DZ twin correlations. The use of the statistical package Stata shows how to change the alpha and power values if estimated correlations from a study differ from those shown in the tables. Finally, a list of helpful references is appended to the end. This guide is available at: https:// www.twins.org.au/images/Research/Headers/TRA_Sample_Size_ Guide_20190919.pdf.

\section{In the News}

\section{Twins' Same Day Births}

Two sets of twins have given birth to babies on the same day. Bao Nhia Julia Yang and Bao Kou Julie Yang, who claim to be identical, are from Fresno, California. The sisters gave birth to daughters just two hours apart at their city's Community Regional Medical Center. The twins are 23 and come from a family of 14 children (Associated Press, 2019). Another pair, Lisa Boyce and Lauren Kozelichki, who appear to be fraternal, are from Creve Coeur, Missouri. They delivered their newborns on the same day despite the fact that their due dates were days apart. Lisa went into labor, requiring a $\mathrm{C}$-section on the same day that her sister's C-section had been scheduled. The deliveries took place 10 hours apart. Interestingly, one of the twins gave birth to a pair of twins (ABC News, 2019).

\section{Death of a Twin Holocaust Survivor}

Eva Kor, who co-founded CANDLES (Children of Auschwitz's Nazi Deadly Laboratory Experiments Survivors) with her identical twin sister Miriam, passed away in July 2019 at age 85 years (Goldstein, 2019). CANDLES attracted over 100 twins who had been the subjects of Dr Josef Mengele's horrific medical experiments conducted in the Auschwitz-Birkenau concentration camp between 1943 and 1945 (Segal, 1985). I traveled with Kor and others to Auschwitz, in Poland, and to Yad Vashem (Hand and Name) in 1985 to attend the 40th anniversary reunion of the twin survivors and a three-day public hearing on Mengeles' war crimes. Kor also created the CANDLES Holocaust Museum and Education Center in her home town of Terre Haute, Indiana.

\section{Identical Vindman Twins}

Alexander Vindman arrived in the USA from Ukraine with his family and identical twin brother Yevgeny when they were three years old. They were raised in a section of Brooklyn, New York known as 'Little Odessa'. Alexander is a Lieutenant Colonel and a top Ukraine expert in the National Security Council of the USA. His twin brother is a former major in the USA army and a White House attorney. Alexander testified in Congress as to the nature of a telephone call between President Trump and the President Zelensky of Ukraine. The possibility that Yevgeny, who goes by the name Eugene, would be called to testify was raised (News, 2019; Steinbuch, 2019).

\section{Twin Festival in France}

A festival of twins is held annually in the town of Pieucadeuc, located in the northwestern part of France (BBC News, 2019). Summer 2019 marked the 25th year that the event has been ongoing. It is estimated that 1500 twins and higher order multiples participated in the games, music and parade. This festival might offer a good opportunity for researchers, although such events tend to attract mostly identical twins.

\section{Tiniest Twins}

Twin boys, Ashley and Joe, were born on April 16, 2019 at 23 weeks' gestation to Talia Keates of Trowbridge, Wiltshire in the UK. They were not expected to live, but were discharged after 129 days in intensive hospital care. They are believed to be the smallest twins to survive. The twins had 'separate sacs', but their zygosity was not indicated. Both twins suffer from chronic lung disease due to their prematurity. However, they are thriving and showing social behaviors in the form of smiling and laughing (Barker \& Wooler, 2019).

\section{References}

ABC News. (2019, November 9). Twin sisters give birth on the same day. https:/abc13.com/society/twin-sisters-give-birth-on-the-same-day/5686575/

Associated Press. (2019, November 7). California twin sisters give birth on the same day. https://globalnews.ca/news/4640204/california-twin-sisters-givebirth-on-the-same-day/

Baker, L. A., Barton, M., Lozano, D. I., Raine, A., \& Fowler, J. H. (2006). The Southern California Twin Register at the University of Southern California: II. Twin Research and Human Genetics, 9, 933-940.

Barker, D. (2004, April 20). Norris McWhirter: Guinness Book of Records co-founder and political campaigner. The Guardian. https://www.theguardian. com/news/2004/apr/21/guardianobituaries.obituaries

Barker, W., \& Wooler, S. (2019, November 11). Mini miracles: World's tiniest twin boys defy the odds after being born at 23 weeks and weighing less than $1 \mathrm{lb}$ each. The Sun. https://www.thesun.co.uk/news/10318673/worlds-tiniesttwin-boys-23-weeks-one-pound/

BBC News. (2019). Twin festival in northwest France reached 25th year. https:// www.bbc.com/news/av/world-europe-49364929/twin-festival-in-northwestfrance-reaches-25th-year

Cederlöf, R., Friberg, L., Jonsson, E., \& Kaij, L. (1961). Studies on similarity diagnosis in twins with the aid of mailed questionnaires. Acta Geneticae. Statistica. Medica, 11, 338-362.

Dite, G. S., Scurrah, K. J., \& Cutler, T. L. (2019). Twins Research Australia: Sample Size Guide. https://www.twins.org.au/images/Research/Headers/TRA_ Sample_Size_Guide_20190919.pdf

Engel, G. L. (1974, February 20). Mourning and anniversary reactions to the death of a twin: Fragments of 10 years of self-analysis (Helen Ross Lecture). Chicago, IL: Chicago Psychoanalytic Institute.

Engel, G. L. (1975). The death of a twin: Mourning and anniversary reactions. Fragments of 10 years of self-analysis. International Journal of Psycho-Analysis, $56,23-40$.

Goldstein, R. (2019, July 8). Eva Kor, 85, victim of Mengele's experiments on twins at Auschwitz, dies. New York Times, p. D9.

Hatemi, P. K., \& Verhulst, B. (2015). Political attitudes develop independently of personality traits. PloS One, 10, e0118106.

Lewis, A., \& Lewis, M. (2013). Tell me who I am. London: Hodder \& Stoughton. McWhirter, N. (1976). Ross: The story of a shared life. London: Churchill Press Limited.

News. (2019). Alexander Vindman's family: 5 fast facts you need to know. https://heavy.com/news/2019/10/alexander-vindman-family-wife-parentsbrother/ 
Nguyen, Q. T. R., Groos, E., Leclair-Visonneau, L., Monaca-Charley, C., Rico, T., Farber, N., \& Arnulf, I. (2016). Familial Kleine-Levin syndrome: A specific entity? Sleep, 39, 1535-1542.

Peraita-Adrados, R., Vicario, J. L., Tafti, M., García de León, M., \& Billiard, M. (2012). Monozygotic twins affected with Kleine-Levin syndrome. Sleep, 35, 595-596.

Schwartz, J. A., Jessick, S., Calvi, J. L., \& Granger, D. A. (2019). Co-twin relationship quality as a moderator of genetic and environmental factors on urinary cortisol levels among adult twins. Psychoneuroendocrinology, $108,118-126$.

Segal, N. L. (1985). Holocaust twins: Their special bond. Psychology Today, 19, $52-58$.

Segal, N. L. (2017). Twin mythconceptions: False beliefs, fables, and facts about twins. New York: Elsevier.
Segal, N. L. (2019a). Evolutionary perspectives on the loss of a twin. In T. K. Shackelford and V. Ziegler-Hill (Eds.), Evolutionary perspectives on death (pp. 25-36). New York: Springer Nature.

Segal, N. L. (2019b). The rare sides of twin research: Important to remember. Twin Research and Human Genetics, 22, 419-424.

Steinbuch, Y. (2019, November 1). Vindman's identical twin may be called to testify in impeachment probe. New York Post. https://nypost.com/2019/11/ 01/vindmans-identical-twin-may-be-called-to-testify-in-impeachment-probe/

Ueno, T., Fukuhara, A., Ikegami, A., Ohishi, F., \& Kume, K. (2012). Monozygotic twins concordant for Kleine-Levin syndrome. BMC Neurology, 12, Article no. 31, https://bmcneurol.biomedcentral.com/articles/10.1186/14712377-12-31

York, C. (2019). Genetic influence on political discussion: Results from two twin studies. Communication Monographs, 86, 438-456. 